Article

\title{
Complex Energy Conversion System Analysis: An Overview
}

\author{
Nima Norouzi, Maryam Fani * \\ Department of energy engineering and physics, Amirkabir university of technology (Tehran polytechnic), 424 \\ Hafez Avenue, PO Box 15875-4413, Tehran, Iran \\ *Correspondence: mfani@aut.ac.ir
}

How to cite this paper: Norouzi, N., \& Fani, M. (2021). Complex Energy Conversion System Analysis: An Overview. World Journal of Electrical and Electronic Engineering, 1(1), 21-

33. Retrieved from

https://www.scipublica-

tions.com/journal/in-

dex.php/wjeee/article/view/77

Received: July 7, 2021

Accepted: August 13, 2021

Published: August 14, 2021

Copyright: $\odot 2021$ by the authors. Submitted for possible open access publication under the Creative Commons Attribution (CC BY) license

(http://creativecommons.org/licenses /by/4.0/).

\begin{abstract}
This article describes the optimization models recently applied to the design and operation of power systems towards forming smart grids and identifies trends, barriers, and possible gaps in this area. Models are described to optimize the design and operation of power systems considering renewable energies, distributed generation, microgrids, demand management, and energy storage systems. It was concluded that it is necessary to validate many of the models formulated recently to optimize the operation through tests with real data and on a large scale. Furthermore, demand management and microgrids are aspects in which it is necessary to develop models for optimal power flow. Finally, it is necessary to predict stochastic variables with greater precision so that these models adapt to the real behavior of the system.
\end{abstract}

Keywords: Efficiency Evaluation; Ambidexterity; Network Data Envelopment Analysis; Iran Electricity Industry; Regional Electricity Company

\section{Introduction}

Power systems are in constant development, the progress of cities drives the advancement of electricity supply systems. The great changes that are observed in the current power systems concerning previous decades are evident. These changes aim to increase the efficiency of the systems, reduce the environmental impact caused by the generation of electricity and guarantee sustainability over time.

It has been suggested that one way for the sustainable development of power systems is the creation of smart grids (Smart grids). Smart grids integrate electrical and communications infrastructure with advanced automation and process information technologies [1].

The smart grid concept is broad, and its extension depends on the needs of the system. This term has been defined as a modernization of the energy supply system to automatically monitor, protect and optimize the operation of the interconnected elements $[2,3]$. According to the Electric Power Research Institute (EPRI), some of the benefits expected from the implementation of smart grids are Greater reliability and power quality, security and robustness against risky events, energy efficiency, and environmental effects; financial benefits [2]. 


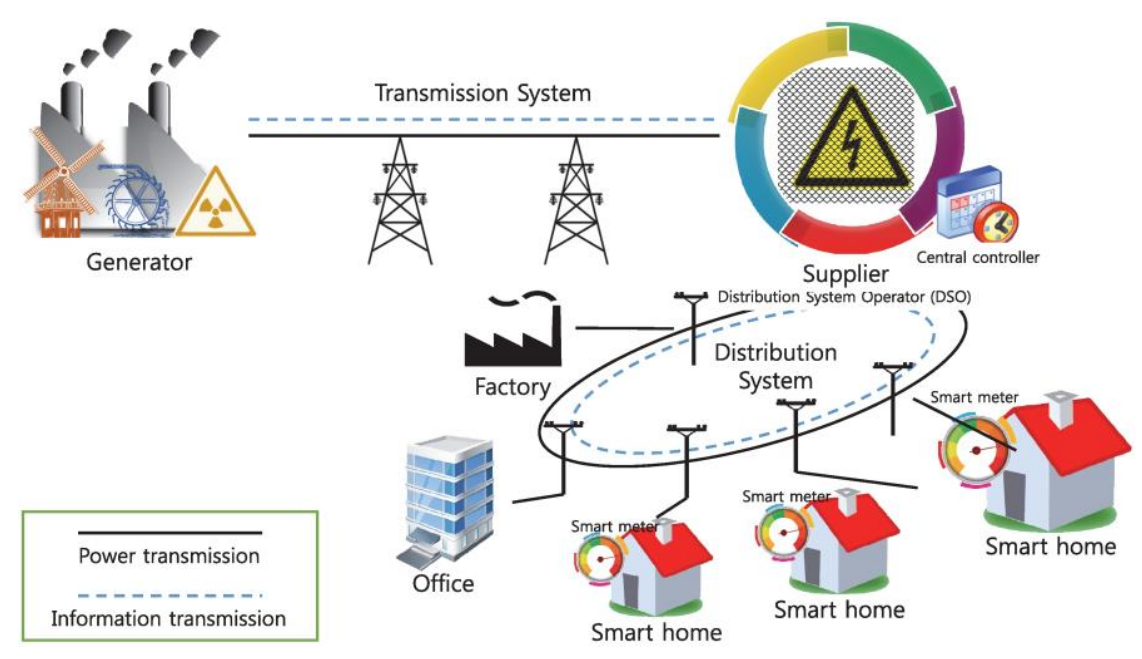

Figure 1. Desirable of smart grids in general and for each stage of the power system.

In Figure 1, a summary of the desirable characteristics of smart grids is shown. Among these, greater efficiency, greater control, and reliability are sought in the electricity supply system, taking into account the characteristics of the network. The requirements of smart grids also add greater complexity to the energy supply system, which generates a series of challenges to be addressed [1,4]. One way to ensure that the implementation of smart grids is truly beneficial for the electricity supply and its sustainability is to apply optimization techniques to minimize or maximize certain desired factors. For example, in planning, optimization makes the most of available economic and environmental resources. In addition, the optimization applied to the operation helps to guarantee technical safety conditions during the operation of the system. Optimization techniques have been applied to power systems since the mid-1960s [5], and they have played an important role in planning and operation. These techniques have been used for different types of problems such as cost reduction in the design of the facilities, minimization of costs in the operation of generation plants, minimization of emissions in thermoelectric plants, minimization of losses in operation, minimization of costs in the design of transmission lines, among others. To solve each optimization problem, it is necessary to develop a model that allows the most appropriate techniques to be applied. An optimization model is a mathematical representation of a system in which a set of decision variables must minimize/maximize an objective function, subject to restrictions [6,7]. Because of the evolution of power systems, the models applied for optimization must integrate the changes made in the structure of these systems so that they can be applied and their results are representative of reality[7-11]. In this sense, this paper initially describes some aspects that have been considered in the most recent research related to smart grids and the new complexity of power systems. Then, the optimization models applied to the design and operation of power systems on the way to creating smart grids are described. Likewise, trends, barriers, and possible gaps in this field of study are identified. Accordingly, this study's main issue is network data envelopment analysis to measure organizational ambidexterity and efficiency of regional power companies in Iran. To achieve this goal, in the continuation of the article, the theoretical foundations of the research are reviewed, and the mathematical model for calculating ambidexterity and efficiency is introduced. After that, the research method will be explained, and in the fourth section, the relevant calculations will be analyzed, and finally, the necessary conclusions will be drawn from the research findings.

\section{Characteristics and current trends of power systems}

At present, for the reduction of environmental impact and sustainability over time, forms of generation based on renewable sources such as wind energy, solar energy and 
hydraulic energy have been implemented. The worldwide installed capacity of these energy sources has reached $1,849 \mathrm{GW}$ for the year 2015, with an increase of $8.7 \%$ with respect to 2014, including hydroelectric generation [8].

In the transmission of electrical energy, greater flexibility and efficiency have been sought, especially over long distances with the use of direct current transmission lines (HVDC: High voltage direct current transmission). This type of system can provide advantages such as power flow control, cost reduction and can allow the interconnection of asynchronous systems [9].

In the field of energy distribution, distributed generation and microgrids are trends that are currently being implemented and that are seen as alternatives to reduce the losses that exist in the transmission of large blocks of energy over long distances. Among the strategies at the distribution level, active demand or demand response, is another way that is being implemented to control the flow of energy in power systems, it is about consumers being able to know their electricity consumption and make decisions that help to improve the operation of the system [10]. However, these technologies have been applied mainly in developed countries and it is an open field of research for them to be in widespread use in the future.

\subsection{Renewable energy}

One of the most important advances in power systems has been the use of new energy sources, especially those that have a lower environmental impact. The generation of electrical energy through renewable sources is growing rapidly, in fact, during 2015 worldwide the installed capacity in GW of renewable energies has exceeded that installed in thermal generation, about 147GW renewable compared to 38GW thermal [8 ]. In such a way that the world trend is towards the growth of renewable energies. In recent years this progression has been evident.

Within renewable energy sources, hydro energy is the one with the highest installed capacity in the world, followed by wind energy and solar energy (Figure 2). However, the installed capacity in photovoltaic solar energy is growing rapidly, in the same way that wind energy has a higher growth rate than hydroelectric. As shown in Figure 3, the growth of wind and solar photovoltaic energy sources has been sustained in the last five years, these growth rates indicate that in the coming years the penetration of renewable energy sources will increase. In such a way that it can be said that electrical systems today and in the future are characterized by a constant increase in the addition of new energy sources with a particular emphasis on renewable energies.

\subsection{Impact of generation variability}

The existence of renewable energies such as solar energy and wind energy, implies that there is a dependence on climatic conditions for the generation of electricity. The nature of the climate is variable, and although there are techniques to predict its behavior, there are always factors of uncertainty. Environmental phenomena can seriously affect the operation of power systems, for this reason interest has been generated in the study of these systems in the face of changes in environmental conditions that may affect generation [11]. 


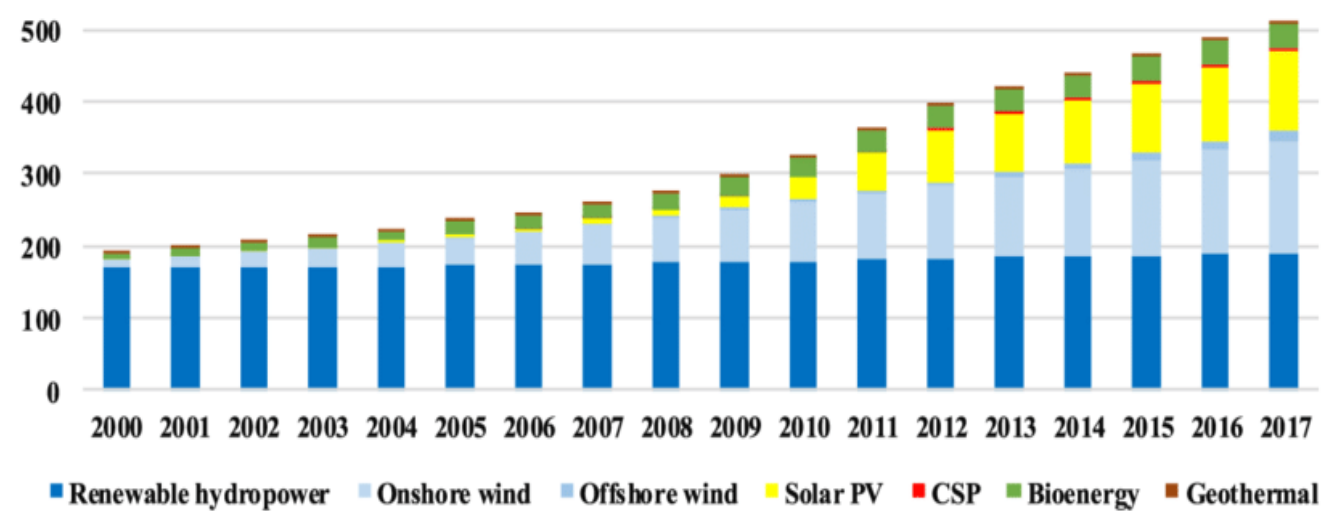

Figure 2. Installed capacity in GW of renewable energies in the years 2000 and 2017. Historical growth of installed capacity in GW of photovoltaic solar energy and wind energy in the last five years.

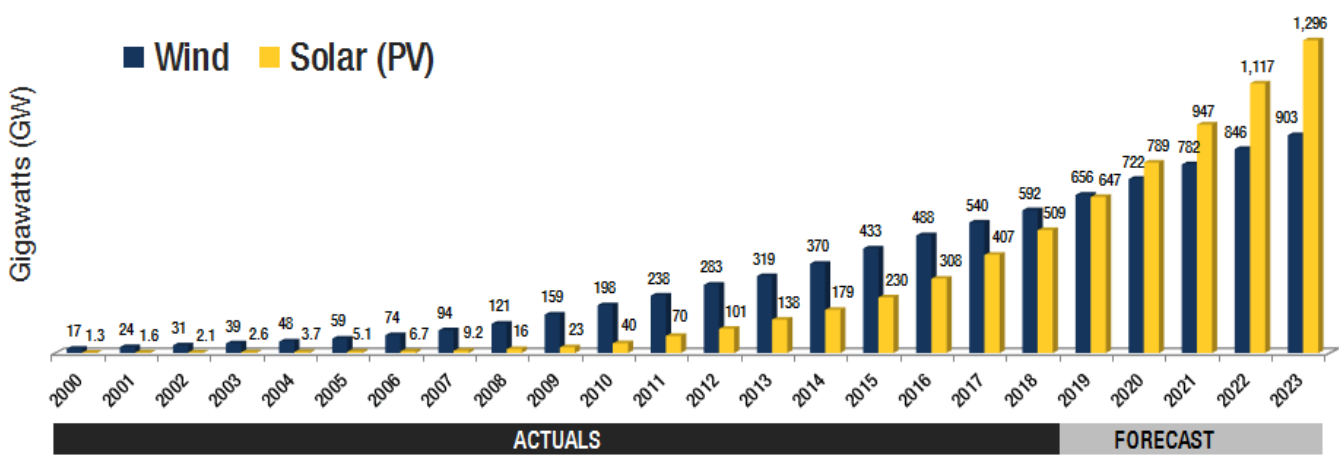

Figure 3. Historical growth of installed capacity in GW of photovoltaic solar energy and wind energy in the last 20 years.

Due to their variability, the high penetration of wind and solar energy can affect the design, operation and planning of power systems. Research has been carried out to verify the impact of this type of generation on the power system. The results have shown that as wind generation exceeds $20 \%$ of the demand, problems can occur with the control of frequency, stability and power balance, in such a way that to maintain the reliability and flexibility of the system it is necessary to increase the power reserves in the system $[13,14]$.

Holttinen et al. propose that integration into large power blocks can help maintain power balance and system reliability through international exchanges [12]. However, this should result in a strengthening of the transmission system to be able to transfer larger blocks of energy and greater monitoring against possible events. On the other hand, the connection of photovoltaic energy to the networks has effects, both in a stable state and in a transitory state. The impact of the integration of photovoltaic energy depends on the level of penetration that it can have in terms of the total demand of the system, as well as the topology of the connection and the type of installation; which can range from residential to large-scale photovoltaic plants. According to Eftekharnejad et al. from penetration levels of $20 \%$ with respect to the total generation, deviations are observed mainly in the system's stress profile [13].

\subsection{Distributed generation}

One of the trends in the supply of electrical energy is distributed generation, in general, it is about providing active power sources directly connected to the distribution network or at the user's point of measurement $[14,15]$. This concept is also known as decentralized or embedded generation. Currently, distributed generation systems are being 
used through different technologies such as thermal generation, renewable energies, fuel cells, among others. Most of these technologies require power electronics to inject power into the grid efficiently and reliably, in addition to guaranteeing the quality of the power supplied. Compared to traditional centralized power systems, systems based on distributed generation can greatly reduce losses in feeders and investments in transmission and distribution networks [16]. These systems allow mutual support with the macro network, a greater use of available equipment and resources and a reliable supply with a higher quality, therefore the efficiency and security of the network can be increased.

\subsection{Flexible AC drive systems}

Flexible alternating current transmission systems (FACTS: Flexible AC Transmission Systems) are power electronic devices that, when installed in an electrical power network, allow the power flow to be regulated and to maintain the stability of the system [17]. They provide the desired impedance, active power and reactive power in order to maintain stability on all buses; increase the load limits and reduce the losses of active and reactive power of the power system. FACTS devices are currently used due to the previously mentioned benefits, and it seeks to expand their application to be able to exercise greater control over energy exchanges that help maintain the balance of power and stability in the network in the face of possible variations in generation. or cargo.

\subsection{Direct current transmission}

In recent times there has been a trend towards direct current transmission (HVDC: High voltage direct current transmission) due to the advantages that have been evidenced over AC lines. Among the advantages are the reduction of losses due to the fact that reactive power does not circulate in HVDC systems; In addition, the transmission capacity in HVDC is greater because there is no skin effect and the use of fewer conductors implies lower cost and less weight, over long distances. Additionally, today the efficiency and controllability of AC-DC and DC-AC converters have improved compared to previous times [18]. Thanks to the advantages that have been mentioned, HVDC systems are being used for the connection of offshore wind plants [19], since the inconveniences of AC transmission by underwater cable are reduced. Also, this type of transmission lines is being used for international connections and between networks of different characteristics in terms of frequency and voltage levels, since AC-DC converters with current technology allow to control the frequency of the system and adapt the level of voltage for energy exchange [18]. Initially HVDC technology was based on thyristors, but technology based on transistors has been developed, which allows to obtain almost all the improvements of individual FACTS controllers, that is, transfer of large blocks of power, deliver or absorb a certain amount of power necessary to maintain voltage, quickly control emergencies to avoid very high levels of fault currents, among others [9].

\subsection{Energy storage}

An energy storage system has the ability to be flexibly charged and discharged to accumulate surplus energy and supply it when appropriate [20]. Recent developments in power electronics technologies have made the application of energy storage techniques a viable solution for modern power systems.

Technologies used as energy storage systems include: hydraulic and compressed air pumping systems, batteries, capacitor banks, flywheels, superconducting magnetic energy storage and hybrid storage systems [twenty-one]. Recently, hybrid storage systems have become popular as they allow the benefits of different technologies to be integrated into the same system.

These systems can be applied to solve various problems in current power systems. For example, they can be used to balance the network through auxiliary services, moni- 
toring and load leveling. In addition, it can supply the reserve increase to handle the uncertainty of wind generation, which can help improve the efficiency of the system operation, improve power absorption, lower the cost of fuel and reduce $\mathrm{CO} 2$ emissions [22].

\subsection{Demand management}

In the evolution of power systems towards smart grids, it has been concluded that consumers play a very important role and that they can contribute to improving the performance of the grid. Demand management consists of using incentives to achieve adequate consumption patterns to improve the operation of the power network [23].

The benefits of demand management are technical, economic and environmental. In the technical field, the security and reliability of the network can be increased, since the response time of the demand is much less than that of large generation plants. In the economic sphere, the reduction of demand peaks can be achieved, avoiding additional investments. and in the environmental aspect, polluting gas emissions can be reduced by avoiding demand peaks that are generally covered with thermal generation $[24,25]$.

Demand response programs are strategies that can be applied to achieve a change in end-user consumption, either through changes in the price of energy or through incentives to reduce consumption. Demand response programs can be with direct user participation or through electricity markets or agencies in charge of demand response [26]. In any case, with the use of digital communications and smart energy meters, the demand response becomes a quick control mechanism on the grid.

\subsection{Micro networks}

A microgrid is an independent power system comprising distributed generation, charging, energy storage, and control devices, in which the distributed generation and the storage system are directly connected to the user in parallel [16]. This type of system has been studied since the early 2000s and is proposed as an effective means to convert the distribution network into an active network, which will help the large-scale integration of distributed generation and the transition from the traditional power grid to smart power grids; The idea is to convert energy distribution networks into systems that allow the most efficient management of demand and generation. One of the advantages of microgrids is that they can work in isolation, which allows supplying electrical energy to remote areas.

\section{Optimization models}

The evolution of power systems implies a series of advantages. Advantages include greater flexibility, reliability, and control in energy management. On the other hand, this implies a greater complexity of the system and large investments in up-to-date technology. This leaves an open field for optimization problems, either to achieve appropriate and increasingly efficient designs, to make decisions in cost / benefit dilemmas or to achieve an economic, reliable, sustainable and safe operation.

\subsection{Optimization of renewable energy systems and the impact of resource variability}

Several reviews have previously been made on optimization applied to hybrid systems [27-30]. Taking into account the models, methods and programs that have been used, one of the main aspects to which optimization has been applied is the design of hybrid systems. The models for optimizing the design of hybrid systems have focused on the dimensioning, combinations and location of the components, taking the costs and reliability of the system as the main constraints. In order to evaluate the costs of the design and its reliability, some indices have been used that are shown in Table 1. The fastest growing renewable energy sources have been the focus of more research on optimization. Accordingly, the main focus point has been the systems with wind and photovoltaic generation. The dimensioning and location aspects of these types of energy have been widely addressed [31-34] from the reduction of costs, emissions and increased reliability. Among the recent advances in optimization models for the design of renewable energy systems, 
Rodrigues, Bauer and Bosman reviewed the models available for the design of offshore wind farms and made a proposal for a multi-objective optimization model for the location of turbines. wind power within a pre-designed grid [35]. It is still necessary to carry out different tests and comparisons to this algorithm.

Table 1. Indices to evaluate designs of power systems with renewable energies.

Indicator

Description

\section{Indices for cost evaluation}

(NPC: Net present cost) It reflects the energy cost of a particular system and includes the initial cost

of all system components, the cost of any component replacement over the life of the system, and the cost of maintenance.

(TAC: Total annualized cost) Represents the cost per year of capital plus the annual cost of facility maintenance and repairs. It can be calculated by dividing the net present cost by the present value annuity factor.

(LCC: Life cycle cost)

It is the sum of all recurring and non-recurring costs that take place during the life cycle of a system. Includes purchase price, installation, operating costs, maintenance and residual value at the end of its useful life.

(COE/LCE: Levelized cost of energy) It reflects the cost of energy as a ratio of the annualized cost of the system over the total energy delivered.

\section{Indices for reliability evaluation}

LPSP: Loss of power supply probability It is the relationship between the deficit of power supplied over the electric- $\quad[27,29,30]$, ity demand in a certain period of time.

\begin{tabular}{cc}
\hline $\begin{array}{c}\text { LLP: Load loss probability } \\
\text { UL: Unmet load }\end{array}$ & $\begin{array}{c}\text { It is defined as the period of failure over the total working time of the sys- } \\
\text { tem. }\end{array}$ \\
\hline SPL: System performance level & It is the load that cannot be served over the total time of a period. \\
\hline LOLH: Loss of load hours & $\begin{array}{c}\text { It is defined as the probability of unsatisfied load. } \\
\text { year), the time in which the system cannot supply enough power to supply } \\
\text { the load is quantified, excluding the effects of maintenance and damage to } \\
\text { [20mponents. }\end{array}$ \\
\hline
\end{tabular}

LOLR: Loss of load risk It is defined as the probability that a failure is generated in the system to

cover the daily electricity demand due to deficiencies in renewable energy

sources.

LA: Level of autonomy

It deals with two parameters: the total number of hours in which the loss of

load occurs and the total number of hours of operation. If the autonomy in-

creases, the system will be more reliable, but at the same time the cost in-

creases.

Other indices

Carbon emissions stream

It indicates the level of carbon emissions from a spatial point of view, it is re-

lated to the amount of energy generated or consumed from thermal sources.

CVaR: Conditional value-at-risk

It is a measure of the investment risk, it represents the expected value of the scenarios that are below a certain percentage of deficit.

The approach of modeling the design of hybrid systems as a multiobjective optimization problem makes sense in order to achieve compromises between the different indices that account for the goodness of the systems. This approach has already been used for the design of hybrid systems $[38,39]$ and has been implemented in commercial programs [28].

Other optimization problems that arise are related to the operation of the system. These have been specified with objective functions ranging from cost minimization to loss 
reduction, with restrictions on the state variables of the system. One of the points of interest in optimizing systems with renewable energies such as solar or wind is the variability of these resources. In this sense, proposals have been made to manage the variability introduced by renewable energy sources.

Martinez and Anderson proposed a formulation of the commitment of units with safety restrictions to handle high penetration of variable generation due to renewable sources. The model is formulated as a probabilistic optimization problem (chance-constrained optimization), which allows taking into account the uncertainty in the generation and in the load [40]. For their part, Taghavi et al. proposed a probabilistic reactive power dispatch taking into account the variability of energy sources and other elements of the system such as FACTS and HVDC. The model was formulated as an optimization problem with linear fuzzy logic and discrete strut estimation was applied for the solution. It was shown that this model can be used with less computational load compared to other probabilistic methods such as the Monte Carlo method [41]. However, both proposals still need to be tested with larger-scale systems and real data.

Summers et al. propose a stochastic model for multi-period optimal power flow (FOP), which minimizes operating costs subject to various restrictions. In this work, two new approaches to the FOP with stochastic variables were analyzed: (a) the expected deficit approach and (b) the robust approach in terms of distribution (Distributionally robust), both optimization paradigms under uncertainty. Using simple numerical examples, it was demonstrated that these approaches allow making compromise decisions between cost and risk and that the second one provides greater computational efficiency [37]. However, it is recommended to study in more detail the benefits of this type of optimization and the development of distributed optimization algorithms for application to large-scale systems.

As mentioned, one of the areas that has not been covered in research related to optimization of systems with renewable energies is the adaptation and application of the models proposed to large-scale networks. It can be said that the models presented are still in the testing phase and it is necessary to carry out tests with real data.

\subsection{Models for the design and operation of distributed generation and microgrids}

Currently there is a growing interest in the development and improvement of programs and algorithms for the optimization of the design of distributed generation systems. These techniques must cover the main design details, evaluate the risk considering the uncertainty and have high precision in the search for the solution. In relation to distributed generation planning, the proper location of the units plays a crucial role in improving the performance of the system; therefore the optimal location of distributed generation in power systems has been a point of interest in current research. Additionally, distributed generation from renewable sources brings with it variability and uncertainty. In this sense, Atwa and El-Saadany proposed a probabilistic technique for the localization of distributed wind generation formulated as a mixed integer linear optimization problem, which showed more precise results than other methods based on capacity factors [42]. Abdelaziz et al. designed an algorithm to model distributed generation based on renewable sources for planning unbalanced networks. They were able to integrate probabilistic models of the load, wind generation and photovoltaic generation, and determine the optimal location of the generation in the distribution system. With this, a considerable reduction in annual losses due to the integration of distributed generation was obtained [32].

Other works such as Peng et al. They have also focused on the optimal location of distributed generation through statistical methods. However, the model used in this research differs by taking into account the minimization of pollutant emissions together with costs and losses [43].

On the other hand, Shahzad et al. introduced the concept of load concentration factor (LCF) to optimize the location of distributed generation, the proposed method simplifies the necessary calculations to minimize losses and adapt the stress profile [44]. The load 
concentration factor indicates the amount of load connected at a certain point in the power system.

Theo et al. recently reviewed planning and optimization techniques for distributed generation and highlighted the main aspects to improve in this area [45]. Among them:

- Assessment of renewable resources: Employing modern techniques for forecasting meteorological data can improve the reliability of designs.

- Generation models: these are currently very specific, so it is necessary to generalize them and develop models for new technologies.

- Load model: particularly in the industrial field, it is recommended to inquire about the impacts of different types of processes on electricity demand.

- $\quad$ Energy storage model: it is required to develop detailed models of storage systems according to current technology.

On the other hand, there is a need to improve the dispatch of distributed generation so that the operation of the system is as efficient as possible. In this area, distributed generation dispatch models have been developed that take into consideration technical and economic criteria to optimize the operation of the grid, among them the one developed by Ansarian et al. [46], which is based on a fuzzy multiobjective function to simultaneously optimize costs, reliability, losses and stress profile.

Distributed generation and microgrids are widely related. It can be said that microgrids are a natural evolution of distributed generation. In fact, the first concept introduced by Lasseter et al. defines them as a solution to take advantage of the potential of distributed generation by integrating them to the loads, where the set of loads and microgenerators operates as a single system supplying power and heat [47]. According to the review carried out by Fathima and Palanisamy, the investigations regarding the optimization of hybrid generation systems and micro-grids have focused mainly on economic and environmental aspects, although the restrictions that guarantee energy quality and stability are also important. of the system for interconnection with the network [27].

The design of isolated microgrids has been formulated as an optimization problem, which allows obtaining the appropriate sizes of the components, minimizing costs and restricting the LPSP [48]. Recently, different formulations have been made for the problem of sizing microgrids taking into account hybrid generation and energy storage [49-51]. According to Gamarra et al. [52] sensitivity analysis has been revealed as a critical step in microgrids planning to develop a robust design in terms of economic feasibility.

In terms of controlling the operation of the system, one of the most important problems is deciding the mode of operation of the microgrid, that is, to operate connected to the main network or to operate in island mode. In the case of isolated microgrids, active and reactive power dispatch formulations have been made, and optimal power flow considering the integration between conventional energy sources and renewable sources [5356]. On the other hand, the operation of micro networks connected to a macro power system has been considered. In this sense, the power network has been modeled as a "system of systems" through a control strategy that incorporates distributed energy resources, storage devices and loads; an objective function is used to minimize power exchanges between microgrids and guarantee operation within technical limits [57]. However, this approach is preliminary and it is still necessary to formulate a detailed model of optimal power flow for the network with operating microgrids.

\subsection{Flexibility of transmission systems}

As mentioned, the evolution of power systems towards smart grids implies greater flexibility and control in the transmission of electrical energy; FACTS and HVDC transmission make it possible to add these characteristics to power systems.

One of the common characteristics of FACTS and HVDC transmission lines is that they depend on power electronics devices, therefore, one of the points of interest has been 
to integrate these devices to models of operation optimization, such as power dispatch or optimal power flow. In this sense, several investigations have been formulated [58,59].

Recently, Vanitha et al. proposed a method that considers several objective functions for the optimal power flow problem incorporating FACTS devices such as Static Synchronous Compensators (STATCOM). They demonstrated the application of the differential evolution algorithm and fuzzy additive programming with weights for the evaluation of multiple objectives, as a holistic optimal solution to the system [17].

Several authors have tried to integrate HVDC transmission into the formulation of the optimal power flow problem using different models [19,55,60,61]. Mainly models based on heuristic methods and artificial intelligence have been used to deal with the mathematical complexity of power electronics device models.

One of the applications of HVDC transmission is the connection of offshore wind plants. Khraijah and El-Amin proposed a planning model for large offshore wind plants connected by a multi-terminal HVDC transmission system. However, this proposal needs to be implemented in real cases for its complete validation [62-70].

On the other hand, it has sought to optimize the location and adjustment of the FACTS devices in the transmission network, in order to improve the performance of the transmission system. In such a way that different models have been formulated to optimize the localization of the FACTS [71-78].

\subsection{Optimal demand management}

The study [69] reviewed demand response programs, pricing methods, and optimization algorithms. This research obtained some important conclusions for the optimization of demand management:

- Demand response schemes tend to be more successful while end-user participation is higher, therefore these schemes must be attractive and appropriate to the type of user.

- To optimize demand management, accurate prediction of demand in real time is essential, for which algorithms based on fuzzy logic, game theory and neural networks have been applied, but it is a field that still has much to explore.

- Another fundamental pillar to achieve demand management is the availability of accurate system data in real time, which is why technologies for system monitoring will be decisive in the evolution towards smart grids[79-85].

Table 2. Classification of publications reviewed between 2010 and 2016 according to the characteristics of current systems and the type of optimization problem that it seeks to solve

\begin{tabular}{|c|c|c|c|c|c|}
\hline \multirow{2}{*}{$\begin{array}{c}\text { Type of prob- } \\
\text { lem }\end{array}$} & \multirow[t]{2}{*}{ Aspect to optimize } & \multicolumn{3}{|c|}{ Characteristics towards the formation of smart grids } & \multirow[b]{2}{*}{ Energy storage } \\
\hline & & $\begin{array}{l}\text { Renewable Energies } \\
\text { and their variability }\end{array}$ & $\begin{array}{l}\text { Distributed Genera- } \\
\text { tion and Micro Grids }\end{array}$ & $\begin{array}{c}\text { Transmission system } \\
\text { flexibility }\end{array}$ & \\
\hline \multirow[t]{3}{*}{ Design issues } & Costs & {$[31,38,39,62]$} & {$[62]$} & - & {$[38]$} \\
\hline & Reliability & {$[31,38,39,62]$} & {$[62]$} & - & [38] \\
\hline & $\begin{array}{l}\text { Location and di- } \\
\text { mension }\end{array}$ & {$[31-33,35,42]$} & $\begin{array}{l}{[32,33,42,43],} \\
{[44,48,49,51]}\end{array}$ & [63-68] & {$[50,71]$} \\
\hline \multirow{3}{*}{$\begin{array}{l}\text { Operation } \\
\text { problems }\end{array}$} & Units Commitment & {$[72,73]$} & - & - & - \\
\hline & $\begin{array}{c}\text { Active and reactive } \\
\text { power dispatch }\end{array}$ & {$[41,59,74]$} & {$[46,51,54]$} & [41] & [54] \\
\hline & $\begin{array}{l}\text { Optimal power } \\
\text { flow }\end{array}$ & {$[19,37,55,75],[76]$} & {$[53,57]$} & {$[17,19,55,60,77]$} & [57] \\
\hline
\end{tabular}


According to Wang et al. The flexibility of the system demand implies that there may be power quality problems, such as fluctuations in the system voltages, therefore it is recommended to apply the optimal flow of power in $\mathrm{AC}$ and in real time to guarantee the proper operation of the system[70]. However, it is necessary to propose models to integrate demand management strategies into optimal power flow algorithms[86-91].

\section{Conclusions}

Worldwide, many efforts have been made to develop safe, economical and sustainable electric power systems. For this, numerous optimization models have been developed, changing the conception of modern power systems. Table 2 shows a classification of the reviewed publications according to the characteristics of current power systems and the optimization problem addressed. The new trends in optimization models aim to take into account multi-objective functions that allow making trade-offs between different performance indices such as the cost of energy and the probability of loss. Also, stochastic variables have been incorporated that allow modeling the behavior of the system closer to reality, with sources and demand that may vary from one moment to another. After reviewing the most recent works in the field of power system optimization, it is evident that there is much research to be done to achieve the change towards smart grids. In this sense, the following points of interest are raised as possible future research:

- Validation of algorithms for the optimization of the operation of renewable energies that take into account the effects of the variability of these sources. Several models that perform this type of optimization were reviewed, but in almost all cases they have not been validated with real large-scale systems.

- Exact prediction of renewable resources and electricity demand. With the variability introduced by renewable sources and demand management, it is necessary to have an accurate prediction of these values in the future to properly adjust the system and reduce losses and costs while it is possible to increase the reliability of the system.

- Formulate optimal power flow algorithms that can model the demand response and be able to predict the benefits of demand management programs before they are executed.

- Model microgrids for optimal power flow considering their connection to the power system. Although some research has been done in this regard, these are in the early stages and this type of model is needed.

One of the great challenges is seen to be able to obtain models that are closer to the reality of smart grids, since it is expected that in the near future the complexity of the network will increase. The incorporation of communication systems between energy management companies and end users is necessary, but this can lead to other types of vulnerabilities in the network, such as cyberattacks or failures in electronic systems, which must be evaluated. Finally, it is recommended to carry out an exhaustive review of the optimization methods currently applied, since it is an area of research that will allow a solution to the models that are proposed considering the characteristics of smart grids.

Supplementary Materials: Data will be available on any official request from the author(s).

Author Contributions: “Conceptualization, MF and NN; methodology, MF; software, NN; validation, NN, MF and NN; formal analysis, MF; investigation, NN; resources, MF; data curation, NN; writing - original draft preparation, NN; writing - review and editing, MF; visualization, NN; supervision, NN; project administration, MF, All authors have read and agreed to the published version of the manuscript."

Funding: Please add: "This research received no external funding."

Data Availability Statement: Data will be available on any official request from the author(s).

Acknowledgments: Not applicable. 
Conflicts of Interest: "The authors declare no conflict of interest."

\section{References}

[1] McArthur, S.D.J.; Davidson, E.M.; Catterson, V.M.; Dimeas, A.L.; Hatziargyriou, N.D.; Ponci, F.; Funabashi, T. Multi-Agent Systems for Power Engineering Applications - Part I: Concepts, Approaches, and Technical Challenges. IEEE Trans. Power Syst. 2007, 22, 1743-1752.

[2] Markowitz, H. Portfolio Selection. J. Financ. 1952, 7, 77-91.

[3] Konno, H.; Yamazaki, H. Mean-absolute deviation portfolio optimization model and its application to Tokyo stock market. Manag. Sci. 1991, 37, 519-531.

[4] Konno, H.; Koshizuka, T. Mean-absolute deviation model. IIE Trans. 2005, 25, 893-900.

[5] Mansini, R.; Speranza, M. A Heuristic Algorithm for a Portfolio Selection Problem with Minimum Transaction Lots. Eur. J. Oper. Res. 1999, 114, 219-223.

[6] De Silva, L.; Alem, D.; de Carvalho, F. Portfolio optimization using Mean Absolute Deviation (MAD) and Conditional Value-atRisk (CVaR). Production 2017, 27, 1-14.

[7] Liu, S. The mean-absolute deviation portfolio selection problem with interval-valued returns. J. Comput. Appl. Math. 2011, 235, $4149-4157$.

[8] Mansini, R.; Ograczyk, W.; Sparanza, M. Twenty years of linear programming based portfolio optimization. Eur. J. Oper. Res. 2014, 234, 518-535.

[9] Zimmermann, H. Fuzzy Set Theory and Its Applications; Kluwer Academic Publishers: Dordrecht, The Netherlands, 2001.

[10] Zadeh, L. Fuzzy sets. Inf. Control 1965, 8, 338-353.

[11] Zadeh, L. Fuzzy sets as a basis for a theory of possibility. Fuzzy Sets Syst. 1978, 1, 3-28.

[12] Dubois, D.; Prade, H. Possibility Theory; Plenum Press: New York, NY, USA, 1988.

[13] Bellman, R.; Zadeh, L. Decision-making in a fuzzy environment. Manag. Sci. 1970, 17, 141-164.

[14] Fang, Y.; Lai, K.; Wang, S. Fuzzy Portfolio Optimization: Theory and Methods; Springer: Berlin/Heidelberg, Germany; New York, NY, USA, 2008.

[15] Wang, S.; Zhu, S. On Fuzzy Portfolio Selection Problem. Fuzzy Optim. Decis. Mak. 2002, 1, 361-377.

[16] Watada, J. Fuzzy Portfolio Selection and its Applications to Decision Making. Tatra Mt. Math. Publ. 1997, 13, $219-248$.

[17] Tanaka, H.; Guo, P. Portfolio selection based on upper and lower exponential possibility distribution. Eur. J. Oper. Res. 1999, $114,115-126$.

[18] Bar-Lev, D.; Katz, S. A Portfolio Approach to Fossil Fuel Procurement in the Electric Utility Industry. J. Financ. 1976, 31, 933-947.

[19] Madlener, R. Portfolio Optimization of Power Generation Assets. In Handbook of CO2 in Power Systems; Zheng, Q., Rebennack, S., Pardalos, P., Pereira, M., Iliadis, N., Eds.; Springer: Berlin/Heidelberg, Germany; New York, NY, USA, $2012 ;$ pp. $275-296$.

[20] Awerbuch, S.; Berger, M. Applying Portfolio Theory to EU Electricity Planning and Policy-Making; OECD/IEA: Paris, France, 2003.

[21] Roques, F.; Newbery, D.; Nuttall, W. Fuel mix diversification in liberalized electricity markets: A mean- variance portfolio theory approach. Energy Econ. 2007, 30, 1831-1849.

[22] Krey, B.; Zweifel, P. Efficient and secure power for the United States and Switzerland. In Analytical Methods for Energy Diversity and Security: Portfolio Optimization in the Energy Sector: A Tribute to the Work of Dr. Shimon Awerbuch; Bazilian, M., Roques, F., Eds.; Elsevier: New York, NY, USA, 2008; pp. 193-218.

[23] Madlener, R.; Wenk, C. Efficient Investment Portfolios for the Swiss Electricity Supply Sector; FCN Working Paper No. 2/2008; Institute for Future Energy Consumer Needs and Behavior, Faculty of Business and Economics/E.ON Energy Research Center, RWTH Aachen University: Aachen, Germany, August 2008.

[24] Borchert, J.; Schemm, R. Einsatz der Portfoliotheorie im Asset Allokations-Prozess am Beispiel eines fiktiven Anlageraums von Windkraftstandorten. Z. Energiewirtsch. 2007, 31, 311-322.

[25] Glensk, B.; Ganczarek-Gamrot, A.; Trzpiot, G. Portfolio Analysis on Polish Power Exchange and European Energy Exchange. In Multiple Criteria Decision Making; Konczak, G., Michnik, J., Nowak, M., Trzaskalik, T., Wachowicz, T., Eds.; UE Katowice: Katowice, Poland, 2013; Volume 8, pp. 18-29.

[26] Sharpe, W. Capital Asset Prices: A Theory of Market Equilibrium under Considerations of Risk. J. Financ. 1964, XIX, 425-442.

[27] Konno, H. Piecewise linear risk function and portfolio optimization. J. Oper. Res. 1990, 33, 139-156.

[28] Bower, B.; Wentz, P. Portfolio Optimization: MAD vs. Markowitz. Rose-Hulm. Undergrad. Math. J. 2005, 6, 1-17.

[29] Artzner, P.; Delbaen, F.; Eber, J.M.; Heath, D. Coherent measures of risk. Math. Financ. 1999, 9, $203-228$.

[30] Föllmer, H.; Schied, A. Stochastic Finance: An Introduction in Discrete Time; Walter de Gruyter: Berlin, Germany, 2002.

[31] Pflug, G.; Romisch, W. Modeling, Measuring and Managing Risk; World Scientific Publishing: Singapore, 2007.

[32] Rockafellar, R.; Uryasev, S.; Zabarankin, M. Generalized deviation in risk analysis. Financ. Stoch. 2006, 10, 51-74.

[33] Rockafellar, R.; Uryasev, S.; Zabarankin, M. Optimality conditions in portfolio analysis with general deviation measures. Math. Program. 108 2006, 2-3, 515-540.

[34] Ogryczak, W.; Ruszczynski, A. From stochastic dominace to mean-risk models: Semideviations as risk measures. Eur. J. Oper. Res. 1999, 116, 33-50. 
[35] Mansini, R.; Ograczyk, W.; Sparanza, M. Solvable Models for Portfolio Optimization: A Classification and Computational Comparison. IMA J. Manag. Math. 2003, 14, 187-220.

[36] Speranza, M. A Heuristic Algorithm for a Portfolio Optimization Model applied to the Milan stock Market. Comput. Oper. Res. 1996, 23, 433-441.

[37] Carlsson, C.; Fullér, R. On possibilistic mean value and variance of fuzzy numbers. Fuzzy Sets Syst. 2001, 122, 315-326.

[38] Carlsson, C.; Fullér, R.; Majlender, P. A possibilistic approach to selecting portfolios with highest utility score. Fuzzy Sets Syst. 2002, 131, 13-21.

[39] Vercher, E.; Bermudez, J.; Segura, J. Fuzzy portfolio optimization under downside risk measures. Fuzzy Sets Syst. 2007, 158, 769782.

[40] Huang, X. Portfolio selection with fuzzy returns. J. Intell. Fuzzy Syst. 2007, 18, 383-390.

[41] Chen, G.; Liao, X. A possibilistic Mean Absolute Deviation Portfolio Selection Model. In Fuzzy Information and Engineering; Cao, B., Zhang, C., Eds.; Springer: Berlin/Heidelberg, Germany; New York, NY, USA, 2009.

[42] Zimmermann, H. Fuzzy programming and linear programming with several objective functions. Fuzzy Sets Syst. 1978, 1, 45-55.

[43] Vasant, P. Fuzzy production planning and its application to decision making. J. Intell. Manuf. 2006, 17, 5-12.

[44] Madlener, R.; Glensk, B.; Weber, V. Fuzzy Portfolio Optimization of Onshore Wind Power Plants; FCN Working Paper No. 10/2011; Institute for Future Energy Consumer Needs and Behavior, Faculty of Business and Economics/E.ON Energy Research Center, RWTH Aachen University: Aachen, Germany, May 2011.

[45] Madlener, R.; Glensk, B.; Raymond, P. Investigation of E.ON's Power Generation Assets by Using Mean-Variance Portfolio Analysis; FCN Working Paper No. 12/2009; Institute for Future Energy Consumer Needs and Behavior, Faculty of Business and Economics/E.ON Energy Research Center, RWTH Aachen University: Aachen, Germany, November 2009.

[46] Brigham, E.; Ehrhardt, M. Financial Management: Theory and Practice; South-Western CENGAGE Learning: Mason, OH, USA, 2008.

[47] Madlener, R.; Glensk, B. Portfolio Impact of New Power Generation Investments of E.ON in Germany, Sweden and the UK; FCN Working Paper No. 17/2010; Institute for Future Energy Consumer Needs and Behavior, Faculty of Business and Economics/E.ON Energy Research Center, RWTH Aachen University: Aachen, Germany, November 2010.

[48] Nguyen, D.H.; Khazaei, N. Multiagent Time-Delayed Fast Consensus Design for Distributed Battery Energy Storage Systems. IEEE Trans. Sustain. Energy 2019, 9, 1397-1406.

[49] Liu, J.; He, D.; Wei, Q.; Yan, S. Energy Storage Coordination in Energy Internet Based on Multi-Agent Particle Swarm Optimization. Appl. Sci. 2018, 8, 1520.

[50] Xu, D.; Zhang, W.; Jiang, B.; Shi, P.; Wang, S. Directed-Graph-Observer-Based Model-Free Cooperative Sliding Mode Control for Distributed Energy Storage Systems in DC Microgrid. IEEE Trans. Ind. Inform. 2019, 16, 1224-1235.

[51] Bui, V.-H.; Hussain, A.; Kim, H.-M. A Multiagent-Based Hierarchical Energy Management Strategy for Multi-Microgrids Considering Adjustable Power and Demand Response. IEEE Trans. Smart Grid 2016, 9, 1323-1333.

[52] Kondziella, H.; Bruckner, T. Flexibility requirements of renewable energy based electricity systems - A review of research results and methodologies. Renew. Sustain. Energy Rev. 2016, 53, 10-22.

[53] Huber, M.; Dimkova, D.; Hamacher, T. Integration of wind and solar power in Europe: Assessment of flexibility requirements. Energy 2014, 69, 236-246.

[54] Maia, L.K.K.; Zondervan, E. Optimization of energy storage and system flexibility in the context of the energy transition: Germany's power grid as a case study. BMC Energy 2019, 1, 9.

[55] Hilpert, S. Effects of Decentral Heat Pump Operation on Electricity Storage Requirements in Germany. Energies 2020, 11, 2878.

[56] Finck, C.; Li, R.; Kramer, R.; Zeiler, W. Quantifying demand flexibility of power-to-heat and thermal energy storage in the control of building heating systems. Appl. Energy 2018, 209, 409-425.

[57] Luca de Tena, D.; Pregger, T. Impact of electric vehicles on a future renewable energy-based power system in Europe with a focus on Germany. Int. J. Energy Res. 2018, 42, 2670-2685.

[58] Gunkel, P.; Bergaentzlé, C.; Jensen, I.; Scheller, F. From passive to active: Flexibility from electric vehicles in the context of transmission system development. Appl. Energy 2020, 277, 115526.

[59] Jabir, H.; Teh, J.; Ishak, D.; Abunima, H. Impacts of Demand-Side Management on Electrical Power Systems: A Review. Energies 2018, 11, 1050.

[60] Nebel, A. Auswirkung Einer übergeordneten Steuerung Dezentraler Elektrischer Anlagen auf die Höhe des Konventionellen Positiven Redispatcheinsatzes in Deutschland. Ph.D. Thesis, Bergische Universität Wuppertal, Berlin, Germany, 2019.

[61] Lund, P.D.; Lindgren, J.; Mikkola, J.; Salpakari, J. Review of energy system flexibility measures to enable high levels of variable renewable electricity. Renew. Sustain. Energy Rev. 2015, 45, 785-807.

[62] Brown, T.; Schlachtberger, D.; Kies, A.; Schramm, S.; Greiner, M. Synergies of sector coupling and transmission reinforcement in a cost-optimised, highly renewable European energy system. Energy 2018, 160, 720-739.

[63] Krüger, C.; Buddeke, M.; Merten, F.; Nebel, A. Modelling the interdependencies of storage, DSM and grid-extension for Europe. In Proceedings of the 12th International Conference on the European Energy Market (EEM), Lisbon, Portugal, 19-22 May 2015; Inst. of Electrical and Electronics Engineers: New York, NY, USA, 2015.

[64] Gerbert, P.; Herhold, P.; Burchardt, J.; Schönberger, S.; Rechenmacher, F.; Kirchner, A.; Kemmler, A.; Wünsch, M. Klimapfade für Deutschland; BCG, The Boston Consulting Group: Boston, MA, USA, 2018. 
[65] Ringkjøb, H.K.; Haugan, P.M.; Solbrekke, I.M. A review of modelling tools for energy and electricity systems with large shares of variable renewables. Renew. Sustain. Energy Rev. 2018, 96, 440-459.

[66] Morrison, R. Energy system modeling: Public transparency, scientific reproducibility, and open development. Energy Strategy Rev. 2018, 20, 49-63.

[67] Brown, T.; Hörsch, J.; Schlachtberger, D. PyPSA: Python for Power System Analysis. J. Open Res. Softw. $2018,6,4$.

[68] 2020. Available online: https://oemof.readthedocs.io/en/latest/ (accessed on 15 July 2020).

[69] Wiese, F. Renpass Renewable Energy Pathways Simulation System-Open Source as an Approach to Meet Challenges in Energy Modeling. Ph.D. Thesis, Technical University of Denmark, Lyngby, Denmark, 2015.

[70] 2020. Available online: https://wiki.openmod-initiative.org/wiki/Open_Models (accessed on 13 July 2020).

[71] Hörsch, J.; Hofmann, F.; Schlachtberger, D.; Brown, T. PyPSA-Eur: An Open Optimisation Model of the European Transmission System. Energy Strategy Rev. 2018, 22, 207-215.

[72] Repenning, J.; Matthes, F.C.; Eichhammer, W.; Braungardt, S.; Athmann, U.; Ziesing, H.J. Klimaschutzszenario 2050. Studie im Auftrag des Bundesministeriums für Umwelt, Naturschutz, Bau und Reaktorsicherheit (BMUB) 2. Modellierungsrunde, ÖkoInstitut e.V.; Fraunhofer ISI: Berlin, Germany, 2015.

[73] Günther, J.; Lehmann, H.; Lorenz, U.; Purr, K. Den Weg zu Einem Treibhausgasneutralen Deutschland Ressourcenschonend Gestalten; Technical Report; Umweltbundesamt: Dessau-Roßlau, Germany, 2017.

[74] Nitsch, J. Erfolgreiche Energiewende nur mit Verbesserter Energieeffizienz und Einem Klimagerechten Energiemarkt-Aktuelle Szenarien 2017 der Deutschen Energiever-Sorgung; Technical Report; Nitsch: Stuttgart, Germany, 2017.

[75] Henning, H.M.; Palzer, A. Was Kostet Die Energiewende? Wege zur Transformation des Deutschen Energiesystems bis 2050; Technical Report; Fraunhofer-Institut für Solare Energiesysteme ISE: Freiburg, Germany, 2015.

[76] Bründlinger, T.; König, J.E.; Frank, O.; Gründig, D.; Jugel, C.; Kraft, P.; Krieger, O.; Mischinger, S.; Prein, D.P.; Seidl, H.; et al. Leitstudie Integrierte Energiewende; Technical Report; Deutsche Energie-Agentur GmbH (DENA): Berlin, Germany, 2018.

[77] Samadi, S.; Fischedick, M.; Lechtenböhmer, S. Vergleich der BDI-Klimapfadestudie mit anderen Energieszenarien für Deutschland. Energiewirtschaftliche Tagesfragen 2018, 68, 52-57.

[78] Open Power System Data. Data Package Conventional Power Plants; Version 2018-12-20; (Primary data from various sources, for a complete list see URL); OPSD: Berlin, Germany, 2018.

[79] Gerhardt, N.; Böttger, D.; Trost, T.; Scholz, A.; Pape, C.; Härtel, P.; Ganal, I. Analyse eines Europäischen -95\%-Klimazielszenarios über mehrere Wetterjahre Teilbericht im Rahmen des Projektes: Klimawirksamkeit; Teilbericht, Fraunhofer IWES: Kassel, Germany, 2017.

[80] Huneke, F.; Linkenheil, C.P.; Niggemeier, M. Robustheit des Stromsystems bei Extremwetter; Technical Report; Energy Brainpool GmbH \& Co. KG: Berlin, Germany, 2017.

[81] Open Power System Data. Data Package for Load, Wind and Solar, Prices in Hourly Resolution; OPSD: Berlin, Germany, 2019.

[82] Kies, A.; Chattopadhyay, K.; von Bremen, L.; Lorenz, E.; Heinemann, D. RESTORE 2050 Work Package Report D12: Simulation of Renewable Feed-in for Power System Studies; Institute of Physics, University of Oldenburg: Oldenburg, Germany, 2016.

[83] Ruhnau, O. Heat, Wind, and Sun. The Impacts of Electricity-Heat Sector Coupling on the Power System Integration of Variable Renewable Energy Sources; Fakultät für Wirtschaftswissenschaften an der RWTH Aachen: Aachen, Germany, 2017.

[84] Open Power System Data. Data Package Simulated Hourly Country-aggregated Heat Demand and COP Time Series; OPSD: Berlin, Germany, 2019.

[85] Conrad, J.; Schmid, T.; Pellinger, C. Erzeugung von Fernwärmelastgängen aus Temperaturprofilen. ET Energiewirtschaftliche Tagesfragen 2015, 9, 52-54.

[86] Kunz, F.; Kendziorski, M.; Schill, W.P.; Weibezahn, J.; Zepter, J.; von Hirschhausen, C.; Hauser, P.; Zech, M.; Möst, D.; Heidari, S.; et al. Electricity, Heat and Gas Sector Data for Modelling the German System; Technical Report; DIW: Berlin, Germany, 2017.

[87] Lechtenböhmer, S.; Schneider, C.; Yetano Roche, M.; Höller, S. Re-Industrialisation and Low-Carbon Economy-Can They Go Together? Results from Stakeholder-Based Scenarios for Energy-Intensive Industries in the German State of North Rhine Westphalia. Energies 2015, 8, 11404-11429.

[88] Hauck, H. Aluminium-Flex-Elektrolyse als Virtueller Stromspeicher; Trimet Aluminium SE: Essen, Germany, 2017.

[89] Kleinhans, D. Towards a systematic characterization of the potential of demand side management. arXiv 2014, arXiv:1401.4121.

[90] Drosihn, D. Übersicht zur Entwicklung der Energiebedingten Emissionen und Brennstoffeinsätze in Deutschland 1990-2018; Technical Report; Umweltbundesamt: Dessau-Roßlau, Germany, 2020.

[91] Fachgebiet V 1.5-Energiedaten. Zeitreihen zur Entwicklung der Erneuerbaren Energien in Deutschland; Technical Report; Umweltbundesamt: Dessau-Roßlau, Germany, 2020. 